\title{
Dámaso Alonso e a lingüística galega a partir da súa correspondencia (1943-1946) con Ramón Otero Pedrayo
}

\author{
Xosé A. Fernández Salgado ${ }^{1}$
}

Recibido: 04 de mayor de 2017 / Aceptado: 11 de septiembre de 2018

Resumo. Neste artigo lembramos a contribución á lingüística galega de Dámaso Alonso (1898-1990) nas décadas centrais do século XX. Tras anotar algúns datos biográficos sobre el e contextualizar os seus traballos de lingüista dentro da Romanística, nos cales ocupan un lugar destacado os dedicados ó galego, damos a coñecer oito cartas dirixidas a Ramón Otero Pedrayo entre 1943 e 1946. Nelas, Dámaso Alonso solicítalle ó daquela grande patriarca das letras galegas datos de tipo lingüístico; pero a correspondencia revela tamén as súas reflexións sobre o estudo do galego, o seu método de traballo e a súa relación con Galicia.

Palabras clave: Historiografía lingüística; Dámaso Alonso; Correspondencia; Galego exterior, Lingua galega.

\section{[en] Damaso Alonso and the Galician language from his correspondence (1943-1946) with Ramón Otero Pedrayo}

\begin{abstract}
This paper deals with the biography of Dámaso Alonso (1898-1990) and, more specifically, with his contribution to Galician linguistics by the middle of the twentieth century. After having provided some biographical data and contextualized his work as a linguist within the field of Romance Philology, where his studies devoted to Galician had a prominent place, our main purpose has been to analyze the contents of a eight letters with Ramón Otero Pedrayo between 1943 and 1946. The examined correspondence shows the kind of linguistic data requested from the so-called "patriarch of the Galician language" but it also reveals his thoughts on the study of Galician, his working methods, and his relationship with Galicia.
\end{abstract}

Key words: Linguistic historiography; Damaso Alonso; Correspondence; Exterior Galician; Galician Language.

Sumario. 1. Dámaso Alonso e a intelectualidade galeguista de posguerra. 2. Notas biográficas sobre Dámaso Alonso. 3. O Dámaso Alonso lingüista, investigador do galego. 4. O epistolario de Dámaso Alonso a Otero Pedrayo. 5. Fin. Referencias bibliográficas. Bibliografía citada. Bibliografía de Dámaso Alonso sobre o galego. Apéndice: Edición das cartas

Cómo citar: Fernández Salgado, X.A. (2018). Dámaso Alonso e a lingüística galega a partir da súa correspondencia (1943-1946) con Ramón Otero Pedrayo, en Revista de Filología Románica 35, 241-263. 


\section{Dámaso Alonso e a intelectualidade galeguista de posguerra}

Neste artigo danse a coñecer oito cartas de mediados da década de 1940 que teñen por emisor a Dámaso Alonso (1898-1990) e por receptor a Ramón Otero Pedrayo (1888-1976). Nesa correspondencia, datada entre 1943 e 1946, Dámaso Alonso solicita información de tipo lingüístico sobre o galego falado, pero tamén atopamos reflexións do estado das investigacións sobre o galego, o seu desexo de investigalo, o método de traballo que cómpre seguir e a súa relación con Galicia.

As cartas que comentamos, e editamos no Apéndice, fan parte dun proxecto máis amplo, aínda nas fases iniciais, que pretende recadar e estudar a correspondencia científica de Dámaso coa intelectualidade galeguista arredor de mediados do século XX. Nesta investigación, por outra parte, tamén nos resulta de interese a correspondencia en que Dámaso Alonso é asunto das cartas, como ocorre nalgúns epistolarios xa editados nos Cadernos Ramón Piñeiro (CRP) entre Ramón Piñeiro e Ricardo Carballo Calero (CRP V: 2004), Piñeiro e Isidoro Millán (CRP XIII: 2009), Filgueira Valverde e Millán (CRP XVIII: 2011), ou no de Piñeiro a Fernández del Riego (2000). Nesa correspondencia aparecen suxestivas informacións sobre a relación entre o Dámaso Alonso lingüista e o "galeguismo cultural" que vai xermolando arredor da Editorial Galaxia na década de 1950. Nalgúns dos seus fragmentos pálpase o interese do galeguismo por ter na súa "órbita" ó romanista de ascendencia galega, daquela referencia intelectual de primeira orde no Hispanismo, e que ademais estaba interesado en estudar o galego por el chamado "exterior"'. Cómpre ter en conta que situar o idioma galego na Romanística europea foi unha das tarefas fundamentais proxectadas polo grupo Galaxia, onde Ramón Piñeiro desempeñou un papel primordial na súa condición de director literario da editora (véxase Monteagudo 2008). Pode servir de mostra dese interese o epistolario de 1958 de Piñeiro con Millán (CRP XIII: 2009). Nel pode apreciarse a importancia, case obsesión ${ }^{3}$, que para Piñeiro ten que Dámaso Alonso participe no libro Homaxe a Ramón Otero Pedrayo (1958) que a editorial lle preparaba polo seu 70 aniversario. Escríbelle Piñeiro a Millán, que estaba en Madrid (CRP XIII 2009: 89): "Alégrome moito do bó resultado da xestión que fixestedes con Dámaso"; e ante a tardanza na entrega do artigo sinala noutra carta (2009: 90-91)

Teño medo a Dámaso. Inda non piou. ¿Qué demos será o traballo que prepara que tan laborioso lle resulta? Gracias que contamos coa túa vixilante acción diplomática, pois do contrario non sei como llo íbamos a arrincar. Dixémosllo no outono por medio de Vicente Loriente. Il mostrouse moi ben disposto. Agora en cambio retrásase. Craro está que é home moi atafegado e non se lle pode nin se lle debe importunar.

\footnotetext{
O asunto era coñecido pola prensa do momento. En La Noche $(21 / 1 / 1950,8)$ recollíase: "El profesor Dámaso Alonso está haciendo un documentado estudio del gallego de la Asturias occidental. En su paciente investigación atiende no solo a la labor de recoger todas las voces vivas en aquella zona lingüística sino también a su rigurosa transcrición fonética".

Véxanse as cartas [13], [15], [17], [18], [19] e [20], entre o 3/1/1958 e 11/2/1958 (CRP XIII: 2009).

4 Participaría cun estudo sobre as palabras telergas e celergas 'cóxegas' (Alonso 1958). Por outra parte, neste mesmo epistolario atopamos tamén informacións sobre a estrañeza de Dámaso da non participación na Homaxe de Filgueira (carta [30]), sobre a súa posible visita lingüística ós Ancares lugueses e a Limia (cartas [30], [31], [32]), sobre o seu encontro con Aníbal Otero en Madrid (cartas [32], [33], [35], [36]) e sobre a morte do poeta Luís Pimentel, bo amigo de Dámaso (carta [21]).
} 
No presente artigo cinguímonos só a correspondencia de Dámaso Alonso con Otero Pedrayo, que comentamos no apartado 4 e editamos no Apéndice. Nos apartados precedentes lembramos algúns datos biográficos sobre Dámaso así como os seus traballos lingüísticos, o que nos axudará a contextualizar as cartas e asemade o alcance do feito de que unha das personalidades máis sobranceiras da Filoloxía hispánica do século XX se dedicase a estudar o galego a mediados dese século e a reivindicar que se tivese en conta á beira doutras linguas, por exemplo, para explicar problemas non resoltos aínda de Lingüística románica.

\section{Notas biográficas sobre Dámaso Alonso}

Dámaso Alonso naceu en Madrid en 1898, pero con raizame sempre recoñecida por el nas terras da ría de Ribadeo, de onde eran o pai e os ascendentes da nai. Foi poeta destacado da Xeración do 27, historiador literario e creador na crítica literaria da escola chamada "Estilística damasiana", ademais dun gran lingüista e romanista, faceta esta na que elixiu o galego como lingua preferente das súas investigacións dialectolóxicas, fonéticas e léxicas.

Formado na segunda década do século XX no Centro de Estudos Históricos (CEH) á beira da eminencia de Ramón Menéndez Pidal e Américo Castro, fixo posible nun momento histórico complicado, como foron os anos posteriores á Guerra Civil, "salvar y enriquecer la continuidad de la filología española" (Lapesa 1970: 11), que iniciaran os seus mestres do CEH. E iso conseguiuno mercé ás súas investigacións e metodoloxías anovadoras e ó seu labor docente. Todos os alumnos destacan as excelencias de Dámaso como profesor; por exemplo, Lorenzo (1968: 481) escribiu con motivo da xubilación do seu mestre:

Para mi [...] la figura de Dámaso Alonso adquiere una importancia de excepción, porque he podido disfrutar de sus enseñanzas y de su amistad. En mis tiempos de estudiante de Filología Románica en la Universidad de Madrid tanto Dámaso Alonso como Rafael Lapesa imponían su autoridad y magisterio, siempre dispuestos a ayudar a los que nos iniciábamos en la lingüística.

E da mesma opinión son Alonso Montero (2011: 1963 n. 90): “Eu fun alumno de Balbín no curso 1950-51, con quen nada aprendín. Carecía, na Facultade, como Joaquín de Entrambasaguas, de prestixio; non así Rafael Lapesa e Dámaso Alonso, ambos os dous procedentes do CEH"; e mais Alarcos Llorac (2009: 140), quen recoñeceu que "Aquellos dos años de enseñanza damasiana fueron el fruto principal que pude recoger en mis estudios de licenciatura". E o que resulta máis importante, foi sobre todo, como afirmou Lázaro Carreter (1999: 1275)5, un gran mestre "esti-

Lázaro Carreter (1999: 1275) lembra que cando chegou a estudar a Madrid esperaba atopar a Dámaso Alonso explicando literatura, pero a súa sorpresa foi que "era Titular de otra disciplina, Filología Románica [...]. No podía enseñar literatura; las dos cátedras de entonces habían sido cubiertas, y una de ellas por alguien que no le perdonaba sus propias frustraciones, y que, además, poseía gran poder político. Dámaso Alonso, por otra parte, se sentía a gusto explicando Filología Románica, porque, alguna vez me lo dijo, no eran susceptibles de denuncia las teorías sobre la diptongación o la doble $d$ cacuminal". Pola súa parte, Alarcos (2009: 140) indica referíndose ás clases de fonética de Dámaso: "la sabiduría, la claridad y la precisión del Maestro [...] contribuyó a que arraigase en mi una vocación lingüística que reprimió la inicial devoción por la literatura”. 
mulador de vocacións" dende a súa cátedra de Lingüística románica que ocupou na Universidade Central de Madrid dende 1940 ata 1968. Baixo o seu maxisterio directo formáronse algúns dos mellores lingüistas e filólogos da Filoloxía hispánica da segunda metade do século XX, que nun primeiro momento se lanzaron a escribir teses sobre falas de comarcas e aldeas, que algúns ironicamente chamaban "Que verde era mi Valle" (Lapesa 1970: 11), pero que serviron para renovar completamente o coñecemento da dialectoloxía peninsular; outros abordaron a lingüística estrutural, outros cultivaron a estilística e, en fin, tamén algún elixiu enfrontarse cos problemas da ecdótica. Foron discípulos seus, por exemplo, A. Zamora Vicente, Ma Josefa Canellada, E. Alarcos Llorach, Emilio Lorenzo, F. Lázaro Carreter, Félix Monge... E tamén se beneficiaron do seu mestrado os estudantes galegos que naquela altura de mediados do século XX se trasladaban a Madrid para estudar Filoloxía románica, especialidade inexistente daquela na Universidade de Santiago. Referímonos entre outros a Xosé Luís Pensado, o xa citado Xesús Alonso Montero e a Pilar Vázquez Cuesta, estes a finais da década de 1940 e primeiros dos 50; e, xa contra finais desta década, algúns dos integrantes do grupo chamado "Brais Pinto", nomeadamente, o antedito Ramón Lorenzo, Xosé Luís Méndez Ferrín e Bernardino Graña.

En fin, Dámaso Alonso foi numerario da Real Academia Española dende 1945 e o seu director entre 1968 e 1982, e dende 1959 tamén da Real Academia da Historia. Dirixiu a prestixiosa Revista de Filoloxía Española e as coleccións "Biblioteca Hispano-Lusitana" e "Biblioteca Románica Hispánica” da Editorial Gredos. En 1978 recibiría o Premio Cervantes, o máis importante en lingua castelá, e, cando máis novo, tamén o Premio Nacional da Crítica (1927) polo seu traballo sobre as Soledades de Góngora.

As obras completas de Dámaso Alonso, comezadas a publicar en 1972, abranguen 10 voluminosos tomos -o último de 1993, xa póstumo, preparado polo seu amigo V. García Yebra-, o que dá idea da amplitude do seu traballo intelectual ${ }^{6}$. O máis interesante para a lingua galega é o primeiro deles dedicado á súa obra lingüística (Alonso 1972). Nel sobrancean, amais do capítulo inicial sobre a fragmentación fonética peninsular, os traballos sobre dúas áreas lingüísticas en particular: a andaluza e, sobre maneira, a área lingüística do galego, como logo veremos. No tocante ós estudos literarios, dedicou tamén algúns escritos a analizar as obras de Rosalía de Castro e Luís Pimentel ${ }^{7}$.

E aínda que non adoita figurar nas súas semblanzas biográficas, cando menos debe aparecer na súa biografía "galega" o feito de que Dámaso Alonso foi nomeado Correspondente da Real Academia Galega en 1945', e en 1973, recoñecido como Membro Honorario do Instituto da Lingua Galega (Fernández Rei 1994: 161 n.15).

\section{O Dámaso Alonso lingüista, investigador do galego}

A súa faceta de lingüista, que é a que nos interesa neste traballo, quedou adoito agochada nos estudos sobre el e a súa obra polas outras súas facianas de escritor e crítico

Exemplo desta prolixidade tamén son as 524 referencias bibliográficas da súa autoría que compendia Huarte Morton (1970) entre 1917 e 1970; e téñase en conta que Dámaso aínda vivirá ata 1990.

Algunhas cartas de Dámaso a Pimentel poden lerse no BGL (1990).

Véxase o Boletín da Real Academia Galega, n 281-284, p. 330, de 1945. 
literario. E certamente, é a de lingüista a máis serodia e a que desenvolve en menos tempo. Os seus primeiros traballos importantes estritamente lingüísticos datan de principios da década de $1940^{9}$ e Temas y problemas de la fragmentación fonética peninsular, a súa obra cimeira, é de 1962. A partir desta data, os traballos que publique serán xa, polo xeral, de estudos redactados ou realizados, total ou parcialmente, con anterioridade a ese ano. Poderiamos preguntarnos, entón, cómo chega Dámaso Alonso á lingüística e ó galego en torno a 1943, xa con case 40 anos de idade, que había uns poucos anos publicara a súa tese sobre Góngora (1935), que estivera de profesor por Leipzig (1935-1939) e que está a escribir nese intre o seu influínte e desarraigado poemario Hijos de la Ira (1944).

Aínda que de mozo no $\mathrm{CEH}$ a formación que recibira abranguía integralmente os eidos da literatura e da lingüística, Dámaso Alonso vaise facer lingüista sobre todo cando debe facerse cargo en 1939 da cátedra de Lingüística románica na Universidade Central de Madrid -sucedendo ó seu mestre Menéndez Pidal-, e polo papel que xoga no novo Centro Superior de Investigacións Científicas (CSIC) -e dentro del no Instituto Antonio de Nebrija-, que viñera substituír na España franquista ó CEH.

De todos os xeitos, como xa apuntamos, en 1936 Dámaso estaba pola Universidade de Leipzig e alí asistira a un curso do romanista Walter von Wartburg sobre problemas e métodos da lingüística. Conforme o propio Dámaso recoñece (Alonso 1951: VIII), quedara fascinado tanto polo pedagóxico das súas clases coma pola focaxe de estudo proposto que mesturaba diacronía ("evolución") e sincronía ("estrutura"). Wartburg xa era coñecido nese intre precisamente por Evolution et estructure de la langue française (1934). Dámaso propoñeralle ó profesor suízo que poña por escrito os contidos daquel curso nun libro e el, pola súa parte, ó mesmo tempo, comprometíase a traducilo e anotalo con exemplos do castelán -ó final apareceron tamén exemplos do galego e do asturleonés ${ }^{10}$, pois a exemplificación de Wartburg era maioritariamente do francés e do italiano. De aí xurdiría a tradución ó español deste manual Problemas y métodos de la Lingüística, feita polo propio Dámaso Alonso e Emilio Lorenzo, que por vicisitudes varias non se publicaría ata 1951 (Alonso 1951: IX n. 1), ben que o groso da tradución estaba realizada dende 1946, isto é, ó tempo que Dámaso está redactando algúns dos seus traballos iniciais sobre o galego, como os que tratan das voces sotaque ou xuio e xuilín (Alonso 1943, 1944, respectivamente), e que mantén a correspondencia con Otero Pedrayo que aquí presentamos.

É durante este traballo de tradución e adaptación da obra de Wartburg cando se dá conta do atraso dos estudos lingüísticos hispánicos. Láiase no seu prólogo á tradución (Alonso 1951: VI): “¿Qué cantidad de materiales lingüísticos recogidos por las regiones de Francia! En comparación, iqué pocos podría ofrecer la lingüística española!”. E era certo. Por iso, neses anos da década de 1940 e nas seguintes, Dámaso Alonso vai promover entre os seus estudantes e doutorandos traballos e teses de recollida da lingua oral que tiñan a forma de vocabularios, de narracións orais anotadas foneticamente, de pequenas gramáticas de falas dialectais..., maiormente

Así e todo de 1923 é un pequeno traballo sobre as palabras nabija, llanta, pelaire e de 1931, outro sobre a distinción entre "B" e "D" fricativas, publicados os dous na Revista de Filoloxía Española.

10 Documentamos, por exemplo, comentarios ou citas sobre a gheada (n. 17), a voz xebrar (n. 28), os adverbios de dúbida quizáis, quizabe(s) (n. 109), a palabra rego (n. 133), a xerga dos canteiros (n. 134), a denominación muslo para 'biceps' (n. 144), as voces rebolladeiro, reboladeiro, e rebollar, rebolar 'rodar' (n. 154), o "saúco" (n. 162), a orixe onomatopeica de chucho 'bico' (n. 180), etc. 
de zonas arredadas, onde, de antemán, se supuña que ían aparecer trazos lingüísticos particulares e arcaizantes, coma as de León, Asturias, Estremadura ou Andalucía.

Pero se os materias lingüísticos dialectais sobre o castelán e o leonés eran escasos -en comparación por exemplo cós do francés-, as descricións lingüísticas sobre a lingua galega naquela altura de mediados da década de 1940 eran case inexistentes. E desa precariedade vai queixarse reiteradamente Dámaso nos traballos que vaia publicando nas décadas seguintes. Unha das súas primeiras reflexións aparece en 1959 nunha nota do seu traballo sobre o ancarés (Alonso 1972: 316-317 n. 2):

No sabemos apenas nada de lo que es la verdadera imagen de la rica variedad fonética en el gallego hablado de Galicia. Es lamentable el contraste entre la escasez de estudios lingüísticos gallegos, hechos con criterio ciéntífico, y el enorme y fructífero esfuerzo de los especialistas catalanes.

Fragmentos similares atopámolos ó longo de La fragmentación fonética peninsular (1962). Comenta, por exemplo, a propósito da comparación do sistema vocálico galego cos doutras linguas da Romania, a dificultade que supón na súa descrición a case inexistencia de estudos sobre o galego falado (Alonso 1972: 31):

He aquí una enorme dificultad, porque debido al increíble atraso de los estudios de lingüística gallega, esta lengua, en su estado moderno, es casi una incógnita; lo es desde luego, su vocalismo. Falta casi completamente una recogida sistemática de materiales; labor de años.

E nas conclusións deste apartado, insiste na necesidade de contar con recollidas rigorosas e metódicas de datos á hora de facer lingüística: "Si pensáramos en Galicia y en el aspecto fonético, podríamos decir que está por hacer casi todo" (Alonso 1972: 37-38). Esta mesma idea aínda a volve expresar na "Nota inicial" de caracterización do galego dos Oscos asturianos: "La dialectología del gallego está absolutamente en ciernes" (Alonso 1972: 499) ${ }^{11}$.

Non é este o lugar de analizar o porqué do atraso dos estudos de lingüística galega a mediados do século XX. Unha panorámica desa situación pode verse nos traballos de Fernández Rei (1994), Regueira (1996) e Santamarina (2005). Dende logo, nesas carencias, tiveran que ver a situación social do galego e a prominencia dos aspectos literarios, históricos e etnográficos sobre os propiamente lingüísticos, tanto entre os intelectuais galeguistas do Rexurdimento do século XIX coma nos da época nacionalista das Irmandades da fala e do Seminario de Estudos Galegos do primeiro cuarto do século XX. E isto viña derivado, en parte, do feito de que a Universidade de Santiago carecera dunha licenciatura ou especialidade na que poder formar lingüistas, non conseguida ata 1963 en que se crea a sección de Filoloxía románica ${ }^{12}$.

$\mathrm{Na}$ verdade, arredor de 1940, canto a estudos sobre o galego de certo valor, Dámaso Alonso podía dispoñer como material de apoio dos Diccionarios oitocentistas de Cuveiro (1876) e Valladares (1884); o de Carré (1928-31, 1933); o inconcluso Vo-

11 Queixas semellantes sobre o atraso da lingüística galega nesta altura do século poden lerse en Zamora Vicente e Vázquez Cuesta (Fernández Rei 1994: 157 n.10 e 11).

12 A Facultade de Filosofía e Letras de Santiago creada en 1922 especializárase en Historia, así que os universitarios galegos que querían cursar estudos lingüísticos ou filolóxicos debían trasladarse á Universidade Central de Madrid, onde si existía unha especialidade de Filoloxía románica. 
cabulario popular (1926) de membros do Seminario de Estudos Galegos; o de Acevedo e Fernández, que malia o título de Vocabulario del bable de occidente (1932) recollía voces do galego de Asturias; ou do enxebre Vocabulario castellano-gallego (1933) das Irmandades da fala. De textos gramaticais, dispuña da Gramática gallega (1868) de Saco Arce e dos traballos historicistas Gramática histórica gallega (1909) de García de Diego e El idioma gallego (1935) de Couceiro Freijomil. Ademais, podía consultar en alemán os estudos de carácter dialectolóxico e etnolingüístico feitos por Krüger e os seus discípulos Schneider, Schroeder e Ebeling, sobre todo de zonas lindantes do galego co portugués e o leonés; e tamén algunhas publicacións sobre o portugués redactadas por Leite de Vasconcellos e de etimoloxía, por J. Piel e H. Meier. Por último, había aínda algún modesto traballo de recollida de expresións e refráns, coma o de Noriega Varela Como falan os brañegos (1928), e estudos etnográficos como Terra de Melide (1933), que publicara o Seminario de Estudos Galegos. Xa na década de 1950, xuntaríanse a estes os artigos de dialectoloxía galega publicados por Zamora Vicente, os de etimoloxía e léxico de Aníbal Otero, a monografía de Luís Cortés sobre o galego zamorano de Lubián (1954) e, xa contra os anos finais da década, os tres volumes do Diccionario enciclopédico (1958-1961) de Eladio Rodríguez editados pola Editorial Galaxia. Mesmo algunha das publicacións máis antigas non era xa doado conseguilas nesa altura, pois non estaban xa en circulación. Boa parte destes traballos aparecen referenciados nas súas publicacións.

Xa que logo, non lle faltaba razón a Dámaso Alonso: en 1943 -cando inicia as súas investigacións sobre o galego-, e en 1962 -cando redacta La fragmentación fonética peninsular-, o galego, sobre todo o oral, era unha lingua mal descrita, eiva que non se vería remediada en parte ata a década de 1970. Pero aínda así, malia esa precariedade de descricións, o certo foi que Dámaso acabou decantándose nunha gran parte dos seus traballos lingüísticos por ter como lingua obxecto de estudo o galego. Non obstante, a variedade lingüística elixida para investigar non foi a do "galego interior" -isto é, o falado nas catro provincias administrativas galegas-, senón o que el vai denominar "galego exterior", quer na súa vertente asturiana, o falado entre os ríos Eo e Navia e sobre todo na bisbarra dos Oscos; quer na súa vertente ancaresa, o "galego-leonés", falado no val de Ancares, na parte administrativa leonesa ${ }^{13}$. Ben é certo que nas súas descricións sempre se contrastan as solucións destas zonas coas do "galego interior", nomeadamente coas variedades do lugués lindeiro con Asturias e, cando pode, coas doutras zonas, información que conseguía por medio de cartas e cuestionarios que enviaba a persoeiros da intelectualidade galega e mais a cátedros e directores de Institutos $^{14}$.

Dámaso Alonso (1972: 310) no traballo sobre o ancarés, define o "gallego-exterior o gallego-leonés al hablado fuera de Galicia, en tierras españolas limítrofes con ella. El gallego exterior o gallego-leonés comprende una serie de hablas que son básicamente gallegas, con rasgos que, aunque a veces varían respecto al gallego considerado como normal en Galicia, están dentro del sistema lingüístico galaico si lo miramos en una perspectiva sincrónico-diacrónica [...]. Una rama del gallego leonés es el hablado en el extremo occidental de Asturias, que muchas veces, por rapidez, llamamos gallego-asturiano".

14 Por exemplo, no artigo sobre a voz enxebre de 1947 (Alonso 1972: 293-314 n. 1) salienta nas numerosas notas os modos que tiña para obter a información. Indica que o Sr. Chao Espina, profesor de Instituto, fixera un interrogatorio por escrito en moitas aldeas galegas, o mesmo cós Sres. Montero e Bernis, Catedráticos do Instituto de Lugo, o poeta chairego Iglesia Alvariño e o novelista Torrente Ballester, e cós seus amigos Fernando Parga, Vicente Loriente e Filgueira Valverde. O certo é que por estes medios Dámaso foi quen de obter información en máis de 50 puntos da provincia de Lugo e noutra media ducia de Pontevedra e A Coruña (véxase o mapa en Alonso 1972: 313). 
E agora cabería facérmonos outra pregunta: porque se decidiu a estudar o galego e non outra lingua, e en concreto a variante do "galego exterior"? Cando menos, en primeiro lugar, houberon de pesar razóns emotivas: a súa familia, como varias veces repite na súa correspondencia, procedía da ría de Ribadeo e el mesmo pasara durante a súa infancia moitas tempadas nesta vila da Mariña luguesa: alí nacera o pai, Dámaso Alonso Alonso, e tamén se enterrara, e a ela volvía con asiduidade nos tempos de lecer (véxase Gamallo Fierros 1971, 1972). Ademais, o galego éralle unha lingua coñecida. Nunha entrevista para o xornal El Ideal Gallego (IG 1973) sinalaba Dámaso:

En primer lugar porque aunque yo no he nacido en Galicia, me considero gallego, porque de mis cuatro abuelos, tres lo eran. Segundo porque me crié en Ribadeo. Allí murió mi padre. A mi me gustaba corretear con los "pícaros" como se dice allí, y he hablado gallego con ellos.

Canto a súa nai, Petra Fernández de las Redondas, nacera nunha localidade de Toledo, na Mancha Alta (Las Huecas), pero tiña ascendencia no lugar das Campas, en Castropol (Asturias); xa que logo, tampouco lle era estraña a Dámaso a fala galega da beira asturiana da ría. Para alén destes motivos sentimentais, como intelectual interesado na lingua oral, Dámaso era consciente dos trazos lingüísticos particulares que ofrecía ese galego falado nas Asturias administrativas; e ben seguro que como dialectólogo era coñecedor de que esas peculiaridades aínda se debían acentuar máis tres ou catro ducias de quilómetros cara ó interior, xa nos Oscos (Asturias), bisbarra recóndita e arredada da contaminación lingüística moderna, como adoito buscaban os xeolingüistas nas súas investigacións. De por parte, as terras dos Oscos e do val de Ancares (desde onde baixara a familia dos Alonso a finais do século XVIII) eran lingüisticamente zonas de transición entre os falares galegos e os asturleoneses, e esas zonas eran tamén das preferidas polos romanistas para os seus inquéritos. Finalmente, deberon de influír aspectos académicos, pois a docencia dos contidos relacionados coa Filoloxía galego-portuguesa na Universidade Central estaban adscritos á súa cátedra de Lingüística románica.

Fose o que for, Dámaso Alonso dende 1943 vai contribuír á descrición da área lingüística galega con preto dunha vintena de títulos, polo xeral dende unha focaxe románica. Aparecen recolleitos no tomo I das súas Obras completas no apartado "II. Del occidente peninsular" (Alonso 1972: 293-536) e como o propio Dámaso recoñeceu na entrevista antes citada ( $I G$ 1973): "Mis estudios de lingüística han sido seguramente en un 70 por cien sobre tema gallego".

Trátase de traballos que abordan aspectos léxico-semánticos, dialectais, fonéticos e etimolóxicos de voces da área lingüística galega (véxase Lorenzo 1968, 1990; Fernández Rei 1994), moitas veces tinguidos de contidos etnográficos, como sucede por exemplo no artigo sobre as formas de lle chamar ó sabugueiro ou bieiteiro (Alonso 1946). Dámaso parte dunha palabra, adoito galega ou do galego-asturiano, e pode estudar a súa etimoloxía con todo detalle, coma nos casos de enxebre, bordelo ou ozca (Alonso 1947, 1950, 1955, respectivamente); pode dispensar unha breve clase de fonética histórica, coma cando aborda o desenvolvemento da nasalidade en galego no artigo sobre a palabra engalar (Alonso 1954), ou a evolución das palatais nas voces xuio e xuilín (Alonso 1944-45); pode estudar a súa significación, coma no vocábulo bedro (Alonso 1953); pode explicar como se producen as ampliacións semánticas, por exemplo, a partir dos casos de enxebre e sutaque (Alonso 1947, 1943 respectivamente); ou, en fin, pode establecer a súa variación dialectal, coma 
nos estudos xa citados das palabras sabugo e bieiteiro e tamén de telergas, celergas, celigras... (Alonso 1946, 1958, respectivamente).

Dedicou especialmente tres traballos a nos presentar a fala e a vida dos Oscos (Alonso 1957, 1969, 1976) ${ }^{15}$ a través da transcrición semifonética de varios textos orais recollidos por el mesmo a mediados da década de 1940 -dos primeiros que se realizan deste xeito na historia do galego-, ós que engadiu unha breve caracterización fonética, morfosintáctica e léxica da variedade da zona (Alonso 1969: 152153). Ofreceunos, igualmente, outro estudo sobre o galego falado no val de Ancares (Alonso 1959, con modificacións en 1961), a partir do material recadado en dúas viaxes feitas por el e mais García Yebra en 1954 e 1957 á vertente leonesa desta bisbarra $^{16}$. Na completa descrición que realiza, separa os trazos coincidentes do galego co ancarés (por exemplo, a existencia de gheada, a metafonía verbal ou o infinitivo conxugado), dos trazos comúns entre ancarés e leonés (que son mínimos), para finalmente describir os que son particularizadores do propio ancarés (como a dobre acentuación nunha mesma palabra, a existencia de vogais nasais e a palatalización de /a/ en determinadas condicións).

A esteas contribucións aínda habería que engadir as varias páxinas dedicadas tamén ó galego nos distintos capítulos de La fragmentación fonética da península ibérica (1962), cualificado por Lorenzo (1990: 539) como "libro fundamental" para a especialidade da Filoloxía románica. Nel o galego está moi presente nalgunhas das argumentacións de que Dámaso se fai valer para rebater teorías dos grandes mestres da disciplina románica. Por poñer só un exemplo, derruba unha nova teoría de Lüdtke sobre o vocalismo portugués e español botando man do sistema vocálico galego (Alonso 1972: 35). Neste punto, resultan reveladoras as súas reflexións finais sobre a metodoloxía que calquera investigador debe seguir (Alonso 1972: 37-39), tamén presentes nas cartas que logo comentamos:

A un lado está la rigurosa y metódica recogida de datos; al otro, la interpretación teórica. Esta es imposible sin aquella [...]. Sin conocimiento de la realidad lingüística, actual o histórica, las teorías revolucionarias no serán más que jaulas, mejor o peor construidas, pero sin pájaro.

\section{O epistolario de Dámaso Alonso a Otero Pedrayo}

O epistolario que editamos no Apéndice consta de oito cartas manuscritas ${ }^{17}$ de Dámaso Alonso ó ourensán Ramón Otero Pedrayo ${ }^{18}$. Dúas delas están datadas en 1945;

15 Eses traballos formaban parte dun libro varias veces anunciado pero nunca editado. Huarte Morton (1970: 331), tras o asento bibliográfico número 515, sinala: "Es parte del libro anunciado como Textos gallegoasturianos de los tres Oscos, con el número 102, en PSA, 1958, XI, 475".

16 Ambos aínda realizarían unha terceira viaxe no verán de 1962, mais desta vez á vertente luguesa, á zona de Cervantes, pois querían comprobar se nos Ancares galegos se daban os mesmos fenómenos dialectais ca nos leoneses. Como sinala García Yebra (1973: 346): "Llegamos a Xantes, que iba a ser el centro de nuestras investigaciones. No hallamos, en materia lingüística, nada particular. El habla de la vertiente gallega de los Ancares no presentaba ninguna de las características que tanto nos había llamado la atención en la zona leonesa”. Esta terceira viaxe debeu estar proxectada en 1958, de facermos caso do xa comentado epistolario de Piñeiro a Millán nas cartas [30], [31], [32] (CRP XIII 2009).

17 Para a remisión ó seu contido usamos as siglas ROP seguidas dun número; así [ROP1], [ROP2]...

18 Ramón Otero Pedrayo (Ourense, 1888-1976), intelectual galeguista, grande patriarca das letras galegas, foi 
as restantes carecen dese apuntamento, ben que polas referencias que conteñen podemos encadralas entre 1943 e 1946; isto é, no momento en que Dámaso está a redactar os seus primeiros traballos sobre o galego e precisa contrastar a solución lingüística galega que el coñece coa doutras zonas de Galicia, neste caso de Trasalba, lugar de residencia de Otero Pedrayo. Actualmente este epistolario custódiase na Fundación Penzol en Vigo ${ }^{19}$.

Todas as cartas abordan contidos de interese lingüístico nun sentido amplo. Poderíase dicir que son case auténticos interrogatorios sobre o coñecemento de palabras, ditos e mesmo ás veces de costumes e tradicións. Nelas reflíctese sobre todo a maneira de proceder de Dámaso na investigación filolóxica: o seu rigor, o interese polo coñecemento pormenorizado de feitos concretos, a intuición para ordenalos e explicalos e as precaucións nas conclusións. Os principais asuntos tratados son os seguintes:

1) As palabras e expresións inquiridas. $\mathrm{O}$ asunto primordial de case todas as cartas é o inquérito de Dámaso a Otero sobre palabras -e en menor medida de expresións, coplas, supersticións...-, sobre o seu coñecemento, o uso, algunha variante, algún significado particular, ampliacións semánticas... Varias das palabras e expresións polas que pregunta foron comentadas logo nas súas publicacións: sutaque, bordelo, telergas, celergas, xuio, xuilín, etc.

2) O seu método de traballo. As cartas permiten inferir o método de investigación seguido por Dámaso, que poderiamos resumir nas seguintes características:

a) A investigación parte da lingua oral, para o cal cómpre facer recollida de datos in situ, ben persoalmente ou ben a través do envío de cuestionarios por carta a amigos e coñecidos de distintos puntos do territorio galego e que estes os volvan a utilizar con outros informantes (véxase, por exemplo, en [ROP7]: "mis datos parten del gallego hablado en Asturias y suelen tener comprobación en el gallego de Lugo"; e en [ROP8]: “Quizá después de contestar pudiera V. enviar la adjunta hoja a algún amigo de la región alejada para que contestara también".

b) Busca a precisión na obtención e comprobación de datos para soster as súas hipóteses; obviamente, cantos máis datos poida manexar mellor. Compróbese, a modo de exemplo, en [ROP2]: "Este dato me sería precioso para el estudio semántico de la palabra [sutaque], si V. lo pudiera asegurar un poco"; ou en [ROP7]: "Conozco sabugueiro, samugueiro, baito, baiteiro, bieiteiro, biauteiro, biouteiro, birouteiro, benteiro y binteiro. ¿Puede V. añadir a esta lista? ¿Conoce V. supersticiones en que intervenga el saúco?’.

c) Procura igualmente a rigorosidade na indicación da procedencia dos datos: sexa o lugar exacto de recollida, o informante, a fonte escrita... Destes, a información dialectal é para el primordial. Para exemplo véxase en [ROP5]: “tengo, como casi siempre muchos datos sobre el Este de Lugo y Oeste de Oviedo. Pero me faltan del interior. ¿Quiere V. decirme los nombres tradicionales ahí

membro destacado da Xeración Nós, Deputado galeguista nas Cortes constituíntes republicanas (1931-1933), Catedrático de Xeografía na Universidade compostelá (1950-1958) e Presidente da Editorial Galaxia. Cultivou todos os xéneros literarios, amais de ser autor de varios estudos xeográfico-históricos sobre Galicia. Na altura en que se cartea con Dámaso Alonso, Otero Pedrayo estaba apartado polo réxime franquista (de 1937 a 1948) da súa cátedra no Instituto de Ourense.

19 Quero deixar constancia do meu agradecemento á Fundación Penzol, en especial ó arquiveiro Benito Ramírez e a bibliotecaria Pilar Vilaboy, por todas as facilidades ofrecidas na consulta deste material. 
en Trasalba? [...] Cualquier dato será bien venido (pero le ruego indicación precisa del lugar donde se diga)".

d) É moi importante, así mesmo, seleccionar ben os informantes (que sexan usuarios habituais da lingua e bos coñecederores dela) e o método seguido ó facer a enquisa; Dámaso considera a Otero un sabio do idioma. Así, en [ROP1] vemos: "La fama que V. tiene de gran conocedor de todo lo gallego..."; ou en [ROP8] "Yo le rogaría que preguntara a aldeanos de sitios gallegos bien alejados entre si, y que conozcan bien estas labores".

e) Deben contrastarse as fontes orais e as escritas, os dicionarios co uso oral, e ter unha visión románica do tema abordado, constatando por exemplo o resultado noutras linguas, en especial coas veciñas. Véxase, a modo de exemplo, en [ROP6]: "En el gallego del concejo de Castropol se llama bordelo al "par de encuarte o de refuerzo'. De los diccs. gall's que manejo solo el Voc. cast.-gall de las 'Irmandades da fala' encuentro bordelar como trad. de encuartar, y en Carré Alvarellos bordelo y bordelar; [...] No encuentro la palabra en los diccs. ¿La conoce V.?".

3) O estudo do galego. Outro asunto que sae na correspondencia ten que ver co interese de Dámaso polo galego, pola variante dialectal que el estuda, sobre a súa delimitación e sobre o nome que lle dá ("gallego hablado en Asturias", "gallego oriental"); e tamén atopamos algunha pregunta sobre o galego literario do propio Otero. Así, por exemplo, en [ROP4] lemos: "Me he propuesto (pero Dios dispone) estudiar a fondo el gallego hablado en Asturias, tan imperfectamente conocido. Claro que esto me obligará a estudiar dos fajas limítrofes, la gallega del Este de Lugo, y la gallego-asturiana del Este del Navia. [...] Volviendo al gallego de V. ¿Ha expuesto V. en algún sitio su criterio sobre el gallego literario, y sobre el de V. en particular?".

4) A escaseza de investigacións sobre o galego. Saen á luz neste epistolario algúns dos atrancos con que se topa, por exemplo, amais da súa má saúde que non lle permite facer traballo de campo, a precariedade dos estudos e materiais con que traballar e mesmo as dificultades para conseguir os poucos existentes. Así, en [ROP4] pódese ler: "Desgraciadamente me faltan muchos libros y revistas, que mi largo desinterés por el tema me hizo no reunir"; e en [ROP7] [referíndose á Academia galega], "Lo que iba impreso del diccionario ¿se puede comprar? ¿que otras publicaciones tienen a la venta? Si V. está en relación constante con esos señores le agradecería que les dijera que me enviaran contra reembolso todo lo que tengan". Neste aspecto é máis determinante aínda unha carta de febreiro de 1946 de Dámaso dirixida a Angel del Castillo, daquela tesoureiro da Academia; nela dille:

Me dirijo a V. con ruego de que me indique qué publicaciones de la Real Academia Gallega me sería posible adquirir. [...] Trabajo actualmente con bastante intensidad sobre temas gallegos, pero lucho con la escasez de bibliografía, y tengo que ir a buscarla aquí y allá, y que molestar a bondadosos amigos como D. Armando ${ }^{20}$.

5) A súa ascendencia galega. Dámaso Alonso nacera en Madrid, pero, como xa dixemos, sempre se sentiu fortemente vinculado a Galicia, en especial a Ribadeo e

20 Esta carta inédita atopámola á venda nunha web de internet: $<$ http://www.todocoleccion.net/galicia-coruna-damaso-alonso-carta-manuscrita-angel-castillo-1946 x41742624>; a consulta e transcrición fíxose en xullo de 2015 , revisada en setemebro de 2018 . 
á bisbarra da ría, de onde proviña a súa familia. As referencias a isto aparecen en varias cartas, como por exemplo en [ROP4]: "cuando pasaba yo unos días en la tierra gallega de donde procedo. (De la ría del Eo, de sus dos gallegas márgenes vengo; de la de Ribadeo, por línea paterna y de la de Castropol, por la materna)".

6) Outros. Finalmente, pola carta [ROP6] sabemos do seu nomeamento en 1945 como Correspondente da Academia galega e por [ROP4] e [ROP5] dos libros con que o agasalla Otero Pedrayo, cando menos Vida del Doctor Don Marcelo Macías y García (1943), O mesón dos ermos (1935) e Guía de Galicia (1945), todos da súa autoría.

\section{Fin}

Neste artigo quixemos lembrar a contribución de Dámaso Alonso á lingüística galega, agora que se fan os 120 anos do seu nacemento, e fixémolo a propósito do comentario e edición da correspondencia que mantivo con Otero Pedrayo a mediados da década de 1940. Por esas cartas sabemos do rigor investigador de Dámaso, da precariedade dos estudos sobre o galego nesa altura e do amor que sentía por Galicia e pola súa lingua.

Por dereito propio, Dámaso Alonso merece un posto destacado na historia da lingüística galega anterior a 1962 porque se interesou polo estudo científico do galego vivo nun momento en que case ninguén o facía, porque o deu a coñecer a través dos seus traballos como realidade lingüística autónoma na Romanística europea, porque delimitou e caracterizou o que el denomina "gallego hablado en Asturias", e, cando menos, tamén polas continuas leccións de lexicoloxía e de fonética histórica e sincrónica que sobre o galego abrollan en moitos dos comentarios dos seus traballos.

\section{Referencias bibliográficas}

\section{Bibliografía citada}

Alarcos Llorach, Emilio (2009): "Dámaso Alonso", in Eternidad en vilo. Estudios sobre poesía española contemporánea, pp. 139-148. Madrid: Cátedra.

Alonso Montero, Xesús (2000): Oteriana. Ourense (Trasalba): Fundación Otero Pedrayo.

Alonso Montero, Xesús (2011): Anibal Otero. Lingüistica e política en España na Guerra Civil e no franquismo. Vigo: Xerais.

Alonso, Dámaso (1951): "Prólogo a la tradución", en Problemas y métodos de la lingüística, Walther von Wartburg, pp. V-XI. Madrid: CSIC.

Alonso, Dámaso (1972): Obras completas. 1. Estudios lingüísticos peninsulares. Madrid: Gredos.

BGL (1990) = Alonso, Dámaso/Aleixandre, Vicente/Guillén, Jorge (1990): "Cartas inéditas a Luís Pimentel". Boletín Galego de Literatura 3:111-120.

$C R P$ V (2004) $=$ Alonso Girgado, Luis/Cuquejo Enríquez, María/Fariña Miranda, Carmen (eds.) (2009): Cadernos Ramón Piñeiro. Cartas de Ramón Piñeiro a Reicardo Carballo Calero. Santiago de Compostela: Xunta de Galicia. 
CRP XIII (2009) = Cochón, Luis (ed.) (2009): Cadernos Ramón Piñeiro. Cartas de Ramón Piñeiro a Isidoro Millán. Santiago de Compostela: Xunta de Galicia.

CRP XVIII (2011) = Cochón, Luis (ed.) (2011): Cadernos Ramón Piñeiro. Cartas de Ramón Cabanillas a Isidoro Millán en modo de antífona. Santiago de Compostela: Xunta de Galicia.

Fernández del Riego, Francisco (2000): Un epistolario de Ramón Piñeiro. Vigo: Galaxia.

Fernández Rei, Francisco (1994): “Os traballos de Dámaso Alonso sobre o galego de Asturias e o ancarés. A súa importancia na historia da lingüística galega", in Lingua e cultura galega de Asturias, Francisco Fernández Rei (ed.), pp. 151-170. Vigo: Xerais.

Gamallo Fierros, Dionisio (1971): "El ribadense don Dámaso Alonso y Alonso padre del filólogo y poeta Dámaso Alonso". El Progreso (Lugo, 8/7/1971).

Gamallo Fierros, Dionisio (1972): "Mañana hace un siglo del nacimiento de D. Juan Vicente Alonso". La Comarca (Ribadeo, 9/7/1972).

García Yebra, Valentín (1973): "Tres viajes dialectológicos con Dámaso Alonso". Cuadernos hispanoamericanos 280-282: 339-348.

Huarte Morton, Fernando (1970): "Bibliografía de Dámaso Alonso", in Homenaje Universitario a Dámaso Alonso, reunido por los estudiantes de Filología románica Curso 19681969, pp. 295-332. Madrid: Gredos.

IG (1973) = Bartolomé, Gregorio (1973): "Entrevista con Dámaso Alonso". El Ideal Gallego (A Coruña, 8/2/1973).

Lapesa, Rafael (1970): "Dámaso Alonso, humano maestro de humanidades", in Homenaje Universitario a Dámaso Alonso, reunido por los estudiantes de Filología románica Curso 1968-1969, pp. 9-17. Madrid, Gredos.

Lázaro Carreter, Fernando (1999): "Damaso Alonso, mi maestro", in Cinguidos por unha arela común: homenaxe ó profesor Xesús Alonso, Rosario Álvarez e Dolores Vilavedra (coords.), vol. 1, pp. 1275-1292. Santiago de Compostela: Universidade.

Lorenzo, Ramón (1968): "Dámaso Alonso y su obra”. Grial 22:476-481.

Lorenzo, Ramón (1990): “Dámaso Alonso (1898-1990)”. Verba 17:529-542.

Monteagudo, Henrique (2008): "Ramón Piñeiro, a Editorial Galaxia e a Real Academia Galega (1950-1962)". Grial 177:98-111.

Regueira, Xosé Luís (1996): "Os estudios de lingüística galega”, in Homenaxe á profesora Pilar Vázquez Cuesta, Ramón Lorenzo e Rosario Álvarez (coords.), pp. 47-68. Santiago de Compostela: Universidade.

Santamarina, Antón (2005): “A lingüística galega entre 1960 e 1981”, in 25 anos coa cultura galega: vinte e cinco perspectivas para o século XXI, pp.191-216. Santiago de Compostela: Sotelo Blanco.

\section{Bibliografía de Dámaso Alonso sobre o galego ${ }^{21}$}

1943: "Derivados de lorum y loramen". Revista de Filología Española XXVII:30-31. [OC I, pp. 417-418]

1943: "Portugués sotaque". Revista de Filología Española XXVII:36-47. [OC I, pp. 444456]

1943: "Representantes no sincopados de *rotulare". Revista de Filología Española XXVII:153-180. [OC I, pp. 537-565]

21 A siglas $O C$ I remite ó tomo I das súas Obras completas (Alonso 1972). 
1944-45: “Junio y julio entre Galicia y Asturias". Revista de Dialectología y Tradiciones Populares I:429-454. [OC I, pp. 389-415]

1946: "El saúco entre Galicia y Asturias (nombres y superstición)". Revista de Dialectología

y Tradiciones Populares II:3-32. [OC I, pp. 359-388]

1947: "Enxebre". Cuadernos de Estudios Gallegos II, 8:523-541. [OC I, pp. 293-314]

1950: "Gallego bordelo, abordelar" (Sobre el par de encuarte en el Noroeste de la Peninsu-

la)”. Revista de Filología Española XXXIV:238-248. [OC I, pp. 465-476].

1953: "Portugués estiar". Nueva Revista de Filología Hispánica VII, 1-2:157-164. [OC I, pp. 433-443]

1953: "Gallego-asturiano bedro "estivada"”. Nueva Revista de Filología Hispánica VII:164-169. [OC I, pp. 477-484]

1954: “Gallego-asturiano engalar 'volar' (Casos y resultados de velarización de $-\mathrm{N}-$ en el dominio gallego", in Homenaje a Fritz Krüger, vol. II, pp. 209-215. Mendoza: Universidade Nacional de Cuyo. [OC I, pp. 457-464]

1955: "Gallego-asturiano ozca 'paso entre peñas"”. De Vertgleich ... Festgabe Hellmuth Petriconi, Hamburger Romanistische Studien, pp. 199-204. Hamburgo. [OC I, pp. 485-493] 1957: “Ganado vacuno en San Martín de Oscos”. Archivum VII:5-12. [OC I, pp. 523-533]

1958: “Gallego-asturiano telergas, celergas 'cosquillas'. Asturiano rebelgos, regolbinos "cosquillas", in Homaxe a Ramón Otero Pedrayo, pp. 67-71. Vigo: Galaxia. [OC I, pp. 426-432]

1959: “Gallego-asturiano bolar, 'dar con' 'obtener”'. Hispanic Review XXVII:254-256. [OC I, pp. 422-425]

1959: "El gallego-leonés de Ancares y su interés para la Dialectología portuguesa", in Actas do III Colóquio Internacional de Estudos luso-brasileiros, vol. I, pp. 309-339. Lisboa. [Con modificacións in 1961: Cuadernos de Estudios Gallegos XVI, 48:43-79; e OC I, pp. 315-357]

1962: Temas y problemas de la fragmentación fonética peninsular. Madrid: Suplemento de Enciclopedia Lingüística Hispánica. [OC I, pp. 15-292] (Con varias referencias ó galego.) 1969: "Narraciones orales gallego-asturianas (San Martín de Oscos) I. Recuerdos de niñez y mocedad”. Cuadernos de Estudios Gallegos XXIV, 72-74:140-153. [OC I, pp. 502-516]

1968-69: "Narraciones orales gallego-asturianas (San Martín de Oscos) II. A 'stoupada". Filología [de Buenos Aires] XIII:33-37. [OC I, pp. 517-522]

1976: "Narraciones orales en el gallego-asturiano de los Oscos. Relatos, fórmulas curativas y ensalmos de Carmen de Freixe (San Martín de Oscos)", in Estudios ofrecidos a E. Alarcos Llorach, vol. 1, pp. 31-46. Oviedo: Universidad. 


\title{
Apéndice: Edición das cartas
}

$\mathrm{Na}$ transcrición do epistolario de Dámaso Alonso a Otero Pedrayo somos respectuosos coa lingua orixinal dos manuscritos: apenas uniformamos algúns formatos e substituímos as citas a palabras e exemplos, orixinalmente subliñados, pola cursiva. A súa presentación facémola pola que cremos que é a orde cronolóxica da correspondencia. A información que fomos fornecendo ó longo do artigo coidamos que é suficiente para contextualizar e comprender o contido das cartas; así e todo, nalgúns casos inserimos algunha nota a rodapé que axudan a precisar o datos da exposición.

$$
\text { [ROP1] [1943] }
$$

\author{
Colonia del Zarzal \\ Chamartín, 22 mayo \\ (Prov ${ }^{\mathrm{a}}$ de Madrid)
}

Sr. D. Ramón Otero Pedrayo.

Distinguido señor:

La fama que V. tiene de gran conocedor de todo lo gallego, y el poderme valer de la buena amistad de la Srta. Carmen Galán ${ }^{1}$, me animan a dirigirme a V. con una súplica.

Estudio la palabra portuguesa sotaque. Encuentro en el gallego más oriental (el hablado cerca del Eo en Asturias) la expresión de sutaque 'súbitamente, inesperadamente', que de modo inmediato relaciono con el port. de sotaque que tiene el mismo sentido. En gallego la palabra debe ser una ruina absoluta, en trance de extinción. Encuentro en Villalba (Lugo) de taque (Negóulo de taque 'lo negó en redondo') que creo procedente por falsa separación de de sutaque. Filgueira Valverde ${ }^{2}$ me ha enviado de_sócato 'súbitamente' que explico como cruce de de sutaque y de súbito. Mis preguntas son éstas:

$1^{a}$ ) ¿Ha oído V. en algún sitio en Galicia de sutaque (o cosa parecida) con el sentido de 'súbitamente' o de 'fuertemente' o con otro cualquiera?

$2^{\mathrm{a}}$ ) ¿Ha oído V. la expresión, recogida por mi, de taque? ¿Ha oído V., sino, de seu taque o de o seu taque, o cosa análoga?

$3^{\mathrm{a}}$ ) ¿Ha oído V. de sócato?

Mucho le agradeceré cualquier dato. Mi artículo está ya en prensa ${ }^{3}$. Le agradecería mucho que me contestara lo antes posible.

Perdóneme el atrevimiento. Y mande a éste su atmo. S. que muy de veras se ofrece como amigo

$$
\text { Dámaso Alonso. }
$$

Pensamos que Carmen Galán é a viúva do ourensán Carlos Taboada Tundidor (1880-1935), avogado e militar que en tempos da II República chegou a ser deputado pola CEDA.

2 Xosé Filgueira Valverde (Pontevedra 1906-1996) foi un erudito e especialista en literatura medieval galego-portuguesa, ademais de fundador do Seminario de Estudos Galegos (1923) e mais do Museo de Pontevedra (1927), membro da Real Academia Galega (1942) e director do Instituto Padre Sarmiento de Estudios Gallegos (1944).

3 O artigo sobre sotaque publicouse na Revista de Filología Española (véxase Alonso 1943). 
Sr. D. Ramón Otero Pedrayo

[ROP2] [1943]

Mi distinguido amigo:

Muchas gracias por su carta.

Perdóneme que insista. Es que me ha puesto V. la miel en los labios con su recuerdo -aunque vago- de sutaque en el sentido de "pronto" de una persona. Este dato me sería precioso para el estudio semántico de la palabra, si V. lo pudiera asegurar un poco.

Sea V. bueno, y, por favor, pregunte V. a sus amigos. Seguramente que conoce V. a las personas más empapadas del gallego. La palabra está asegurada (aunque en punto de extinción) en el gallego del NE. pero es posible que -en su ruina- quede algún resto en la parte occidental. Mi artículo está en primeras pruebas, y aun se pueden calcular veinte o más días hasta que se tire.

Claro está que yo le conozco y estimo mucho por sus obras, que me ofrezco a V. para todo y quisiera ser su amigo

Dámaso Alonso.

Sr. D. Ramón Otero Pedrayo

[ROP3] [1943]

Mi distinguido amigo: ¿Cómo le podré pagar tantos desvelos? Los últimos datos sobre sutaque me han sido valiosísimos; me han servido de magnífica comprobación para uno de los puntos más hipotéticos de mi artículo. Claro está que en él cito la colaboración de $\mathrm{V}^{4}$

Llegó además la carta horas antes de que entrara en máquina mi trabajo. Ya está tirado en parte, y en seguida lo recibirá V.

Dentro de 10 o 15 días pienso salir para las tierras del $\mathrm{Eo}^{5}$ (mi procedencia y mi cariño, aunque nacido en Madrid). Hace tiempo que me propongo hacer una explotación sistemática del gallego oriental, en especial del de transición hacia el asturiano ${ }^{6}$. Mi ilusión era empezar este verano. Pero mi gran fatiga nerviosa no me permitirá sino algunas calas, avances para campañas futuras.

Le repito mi agradecimiento de ahora y mi admiración de siempre,

Dámaso Alonso

$* * *$

[ROP4] [1943]

Sr. D. Ramón Otero Pedrayo

Mi querido amigo:

Su carta me llegó, muy retrasada, cuando pasaba yo unos días en la tierra gallega de donde procedo. (De la ría del Eo, de sus dos gallegas márgenes vengo; de la de Ri-

4 Certamente, no seu artigo "Portugués 'sotaque"” (Alonso 1943), na segunda nota a pé de páxina sinala que os datos de Ourense son de Ramón Otero Pedrayo "ilustre cultivador de las letras gallegas".

Refírese ó río Eo, que desemboca no mar Cantábrico formando a ría de Ribadeo.

Véxanse as notas da carta seguinte. 
badeo, por línea paterna y de la de Castropol, por la materna ${ }^{7}$ ). A mi regreso a Madrid encuentro los dos libros de V. que me anunciaba. El de don Marcelo Macías ${ }^{8}$, ya lo conocía, aunque superficialmente, por habérmelo dejado el gran Dionisio Gamallo 9 . La novela ${ }^{10}$ no, y ya he comenzado a leerle, con doble interés, literario y lingüístico, aunque he de confesarle que el léxico no deja de darme dificultades ${ }^{11}$. Mucho le agradezco también las cariñosas dedicatorias que enriquecen ambos regalos ${ }^{12}$.

Mucho me interesa todo lo suyo, y en general, ahora todo lo gallego. Me he propuesto (pero Dios dispone) estudiar a fondo el gallego hablado en Asturias, tan imperfectamente conocido. Claro que esto me obligará a estudiar dos fajas limítrofes, la gallega del Este de Lugo, y la gallego-asturiana del Este del Navia ${ }^{13}$ (pues, contra lo que se suele decir, de Navia al Río Canero ${ }^{14}$, y aún más allá, la lengua es aun predominantemente gallega ${ }^{15}$. Mi programa inicial supone cinco años de trabajo. Ya veremos en qué queda todo, y si las malas posadas y los pésimos caminos no acaban con mis 45 años, ya de huesos demasiados duros. no acaban con mi Desgraciadamente me faltan muchos libros y revistas, que mi largo desinterés por el tema me hizo no reunir.

Volviendo al gallego de V. ¿Ha expuesto V. en algún sitio su criterio sobre el gallego literario, y sobre el de V. en particular? ¿qué normas morfológicas y ortográficas sigue? ¿Predominan en su léxico los elementos de su tierra de Orense? Cuanto me gustaría cogerle con un texto delante y asaltarle a preguntas. Soy un empecatado preguntón, culpa de mi ignorancia.

Mande a este amigo que mucho le admira y quiere.

$$
\text { Dámaso Alonso }
$$

7 Dámaso Alonso nacera en Madrid, pero como ben di na carta [ROP6] fora "por casualidad" e, de feito, sempre sentiu que o seu raizame estaba en Galicia, en concreto na ría de Ribadeo. Seu pai, Dámaso Alonso y Alonso, era enxeñeiro de minas e nacera en Ribadeo; a súa nai, Petra Fernández de las Redondas, aínda que nacida en las Huecas, localidade de Toledo, gardaba ascendencia no lugar das Campas, no concello de Castropol (Asturias), na outra beira da ría, fronte a Ribadeo.

8 Refírese ó libro de Otero Pedrayo Vida del doctor don Marcelo Macías y García, presbitero príncipe de la oratoria y del diálogo, de la cátedra y de la ciencia histórica (1843-1941), publicado en 1943.

9 Dionisio Gamallo Fierros (Ribadeo 1914 - Madrid 2000), profesor e especialista en literatura da época do Rexurdimento galego, foi un bo coñecedor e divulgador da biografía e obra de Dámaso, sobre todo con aquilo que o relacionaba con Ribadeo.

10 Trátase da novela $O$ mesón dos ermos, publicada en 1936.

11 En efecto, os críticos coinciden en que esta é a obra máis lograda de Otero; dela destacan ó exercicio lingüístico que despregou en todo o referido ó rico e expresivo vocabulario rural usado.

12 As dúas obras, coa dedicatoria autógrafa do propio Otero Pedrayo, aínda se poden consultar actualmente na biblioteca particular de Dámaso Alonso que custodia a Real Academia Española.

13 Alude ó río Navia, que nace na provincia de Lugo e desemboca en Navia, xa na costa asturiana.

14 O río Canero, máis coñecido como Esva, desemboca na costa cantábrica, na praia de Cueva, no concello asturiano de Valdés, aínda uns quilómentros máis ó Leste de Luarca.

15 A este respecto, Dámaso Alonso (1972: 91), no seu artigo sobre as voces junio e julio, volverá dicir: "Baste hoy decir que la afirmación ya antigua de que el gallego llega, dentro de Asturias, hasta el río Navia, es justísima, si bien, como es sabido, algunos fenómenos típicamente asturianos penetran al Oeste de esa línea"; e en nota a "río Navia" matiza: "En realidad, el gallego penetra todavía algunos kilómetros al Este del Navia", e cita para iso a autoridade de Menéndez Pidal. 
Mi querido Otero Pedrayo:

[ROP5] [c. 1945]

Entusiasmado con el magnífico regalo ${ }^{16}$. Siento que V. se haya adelantado a mis deseos, pues yo lo hubiera comprado enseguida. Muchas, muchas gracias.

La noticia que da V. en la pag. 216 sobre el "arcedianato de Ribadeo", ¿de dónde procede? ¿España sagrada? Si fuera así le agradecería que me dijera tomo y página.

La obra de Lence Santar sobre el Obispado de Mondoñedo ${ }^{17}$, que V. indica, pg. 210, pero sin lugar, ¿dónde se editó? ¿es venal aún?

Mi q ${ }^{\text {do }}$ Otero: No me quiera V. mal. Estudio los nombres de junio y julio ${ }^{18}$. Tengo, como casi siempre muchos datos sobre el Este de Lugo y Oeste de Oviedo. Pero me faltan del interior. ¿Quiere V. decirme los nombres tradicionales ahí en Trasalba ${ }^{19}$ ?

Hacia el límite gallego asturiano corren unos versillos sobre el centeno que empiezan:

En abril espigas mil

En Mayo todo espigado

En Xuio todo maduro [o todo grainolo]

En Xuilín daseye ${ }^{(1)}$ col foucín [o bótalle a fouce i-o foucín]

etc.

Busco algo semejante en el interior de Galicia. ¿Se usa en algún sitio un diminutivo para designar a Julio? Naturalmente que en muchos sitios le llamaran Santiago o Santa Mariña; en otros a sega o a seitura. Cualquier dato será bien venido (pero le ruego indicación precisa del lugar donde se diga).

Muchas gracias. Y un fuerte abrazo de Dámaso Alonso

(1) Forma del gallego de Asturias [nota do propio Dámaso Alonso]

$* * *$

[ROP6] (1945)

Sr. D. Ramón Otero Pedrayo

Mi querido amigo:

Es V. buenísimo. Cuando yo estaba con remordimientos de deberle carta desde hace muchos meses, recibo el nombramiento para la Academia Gallega ${ }^{20}$. Comprendo que todo es obra de V., pues salvo dos etimologías de poca monta, yo no he hecho por Galicia nada que justifique tal distinción. Si el cariño se premiara con

16 O regalo de Otero Pedrayo é a $2^{\text {a }}$ edición da súa Guía de Galicia: geografía, historia, vida económica, literatura $y$ arte, itinerarios completos por ferrocarril y carretera, publicada en 1945.

17 Eduardo Lence-Santar Guitián (Mondoñedo, 1879-1960) foi arquiveiro municipal e cronista oficial da súa vila, ademais de prolífico escritor. Entre outras, foi autor da obra pola que pregunta Dámaso Alonso, Del Obispado de Mondoñedo (1915), publicada en tres tomos pola Deputación Provincial de Lugo.

18 O artigo publicouse en 1945 na Revista de Dialectología y Tradiciones populares II (Alonso 1944-45).

19 Trasalba é unha parroquia do concello de Amoeiro, a non moitos quilómetros da cidade de Ourense. Nela está a "Casa grande", onde residía Otero Pedrayo, actualmente sede da Fundación do mesmo nome.

20 Dámaso foi nomeado membro correspondente da Real Academia Galega en 1945 (véxase a acta da Xunta xeral no Boletín da RAG n 281-284), aínda que o seu ingreso efectivo atrasouse ata 1947. 
nombramientos académicos, ya me llamaría a la parte. Porque quiero a Galicia como a cosa propia. Gallegos, de las dos orillas del Eo (tan gallega es la oriental como la occidental) tres abuelos míos, gallego, de Ribadeo, mi padre y allí enterrado, nací por casualidad en Madrid y a la tierra paterna fuí ya cuando tenía pocos meses. En la meseta me he sentido siempre desterrado.

Muchas gracias, mi querido, mi buen amigo.

Perdóneme ahora que vuelva a molestarle con preguntas. Tengo redactadas unas notas etimológicas y quisiera comprobar varios extremos.

$1^{\circ}$ ) En el gallego del concejo de Castropol $^{21}$ se llama bordelo al 'par de encuarte o de refuerzo'. De los diccs. galls . que manejo solo el Voc. Cast.-gall de las "Irmandades da fala"'22 encuentro bordelar como trad. de encuartar, y en Carré Alvarellos ${ }^{23}$ bordelo y bordelar. Saco la impresión que es más frecuente la familia representada por gall. y port. soles 'par de encuarte', port. solada (¿gall. también?) 'auxilio que un carro presta a otro por medio de una cuerda' (con evidente relación semántica), gall. solear 'encuartar', etc. ¿Quisiera V. decirme si conoce la palabra bordelo y si puede V. darme algún dato para localizarla en territorio gallego ${ }^{24}$

$2^{\circ}$ ) Un amigo, buen conocedor, me da baborear 'tomar incremento el fuego, dar llamaradas', como usada cerca de Ribadeo en frases como baborea o lume. No encuentro la palabra en los diccs. ¿La conoce V.? Claro que podría haber también existido en formas no idénticas sino próximas como *baborar, ababorear, *ababorar, etc. En el concejo de Castropol ababorear es 'quemarse o agostarse el maíz al ir a echar la espiga por excesivo calor o falta de agua'.

$3^{\circ}$ ) ¿Conoce V. la palabra escapula (o alguna próxima) usada en el Concejo de Castropol en frases como Puxiche eso na escapula 'pusiste eso tan cerca del borde de la mesa, etc., que está a punto de caerse'.

$4^{\circ}$ ) Tengo recogido el verbo apalandrar 'agostarse el maíz, etc.' en el sur de Lugo. ¿Se usa en otras regiones? En Monforte ${ }^{25}$ toma también sentidos secundarios: Tas apalandrado 'estás abatido, deprimido, etc.'

$5^{\circ}$ ) Me interesaría saber si conoce V. alguna palabra gallega relacionada con el port. dialectal cònheiro 'haz de hierba, etc.'

$6^{\circ}$ ) En Ribadeo y Castropol llaman a las 'cosquillas' telergas, en otros sitios del gall-ast. celergas. ¿Conoce V. algo semejante en el interior de Galicia? ${ }^{26}$

Dios mío, me va V. a maldecir. No se moleste demasiado en hacer averiguaciones. No quiero quitarle el tiempo.

Muchas gracias de nuevo y reciba un abrazo de

Dámaso Alonso

\footnotetext{
Castropol é o concello situado na ribeira asturiana da ría de Ribadeo, fronte a esta localidade lucense. Refírese ó Vocabulario castellano-gallego de las Irmandades da Fala, publicado na Coruña en 1933. Alude ó Diccionario galego-castelán, de Leandro Carré Alvarellos (1888-1976), que tivo varias edicións (19281931, 1933, 1951, 1972 e 1979).

24 Sobre iso publicou "Gallego bordelo, abordelar" na Revista de Filología Española (Alonso 1950).

25 Monforte é unha vila lucense ó sur da provincia.

26 O traballo "Gallego-asturiano telergas, celergas "cosquillas'. Asturiano rebelgos, regolbinos 'cosquillas", publicaríase no libro de Homaxe a Ramón Otero Pedrayo (Alonso 1958).
} 


\section{$* * *$ \\ [ROP7] [1945]}

Mi querido Otero Pedrayo

Perdone que le fría a preguntas. Tengo muy avanzado un artículo de etimologías gallegas. Como siempre mis datos parten del gallego hablado en Asturias y suelen tener comprobación en el gallego de Lugo. Pero me suele faltar comprobación (o contraste) en el de las otras provincias. He aquí lo que le quiero preguntar (y no sé si algo de esto se lo pregunté ya en primavera):

$1^{\circ}$ ) Nombres del saúco. Conozco sabugueiro, samugueiro, baíto, baiteiro, bieiteiro, biauteiro, biouteiro, birouteiro, benteiro y binteiro. ¿Puede V. añadir a esta lista? ¿Conoce V. supersticiones en que intervenga el saúco?27 En la Galicia oriental y en Asturias hay muchas, pero ignoro si continúan hacia Occidente. Todos los nombres con $b$ - inicial los conozco solo en el gall. oriental de Lugo. Dígame si se usan también en Orense, etc.

$2^{\circ}$ ) En gall-ast. y gall-oriental xebrar = 'separar' (separar ovejas, separar el ternero de la vaca, separar granos: en unos sitios un sentido; en otros, otro). Para algunos sitios de Lugo me dicen que este verbo es xibar, y en otros acibar. El grito para separar las ovejas (de distintos dueños) en unos sitos es

en otros sería ixebra, xebra! (comprobado por mi)

y en otros

$$
\text { ¡xiba, xiba! }
$$

Lo que estudio es xebre y enxebre ${ }^{28}$. Creo haber dado con la indudable etimología. No conozco otras tentativas sino la de derivarlo de insipidus, que es absurda. Yo parto de separare. Me pregunto si a lo mejor esto está ya dicho y yo estoy descubriendo el Mediterráneo. Si no fuera así, guárdeme el secreto, porque es etimología golosa.

Desde luego la forma etimológica es xebrar; y las otras deben ser contaminaciones (es curioso que los dicc. solo traigan de toda esta familia, cibar. ¿Puede V. aclararme algo o añadirme?

$3^{\circ}$ ) En gall. oriental xuyo 'Junio' y xuilín 'julio'. Estos nombres están prácticamente perdidos, sólo recordados por viejos o dentro de una descripción en verso de las labores del centeno

\section{En xuilín botalle a fouce i-o foucín}

¿Conoce V. algo semejante en Occidente? Y, asociado con esto, ¿hasta donde se usa el diminutivo -ín (foucín, xatín, etc.)? En muchos sitios de Lugo conviven -ín e -iño (y también, sin diminutivo camín y camiño, etc.).

Perdóneme V. Yo bien quisiera poderle servir en algo. Reciba todo el cariño de su

Dámaso Alonso

Disculpe y comprenda mi desazón de estar tan lejos de la fuente viva.

O artigo "El saúco entre Galicia y Asturias. (Nombre y superstición)" apareceu na Revista de Dialectología y Tradiciones Populares (Alonso 1946).

28 O artigo "Enxebre" publicouse en Cuadernos de Estudios Gallegos en 1947, aínda que a súa redacción é de 1945, segundo a nota da versión aparecida en Obras completas I (Alonso 1972: 311, n.35). 
[Aparte] De la Academia Gallega no he vuelto a tener noticia. Yo escribí agradeciendo el nombramiento. Lo que iba impreso del diccionario ${ }^{29}$ ise puede comprar? ¿que otras publicaciones tienen a la venta? Si V. está en relación constante con esos señores le agradecería que les dijera que me enviaran contra reembolso_todo lo que tengan.

También me gustaría comprar el Boletin de la com. prov. de Monumentos de Orense. ¿Sabe si se puede comprar toda la colección ${ }^{30}$ ?

En realidad no tengo nada de gallego antiguo. Si se le ocurre algo que se pueda adquirir, dígamelo.

Muchas gracias.

Mi querido amigo:

[ROP8] [c. 1946]

He leído con honda emoción el poema que V. me dedica, y he leído poco después su Pan Galego ${ }^{31}$. ¡Qué grave voz, qué enraizada en su experiencia vivida, experiencia ya de miles de años! Si la tierra misma parece que canta con V., eterna, virginal. ¡Cómo evocan sus versos el paisaje y la vida con profundidad de siglos! No conozco en poesía galega notas más intensas.

Ahora me dirijo al autor de Pan galego. V. verá la adjunta cuartilla. Por su poema veo que V. contestaría a la primera pregunta con la palabra meda (¡Pero en muchos sitios de Galicia se llama de otros modos!). Parece que su contestación a la pregunta $3^{\text {a }}$ sería eirado ${ }^{32}$ (pero ¿entiende V. por eirado lo mismo que por eira? ¿O por el contrario lo mismo que yo por eirada?

Le aseguro a V. que de los muchos problemas etimológicos que me preocupan, ninguno más que éste: porque nunca he pisado terreno más resbaladizo. El centro de interés está en el gall. parga, voz que encuentro, por primera vez en Carré Alvarellos. No es invención de ese dicc., porque en léxicos dialectales portugueses está bien comprobada y los dicc. portugueses (Moraes, Figueiredo ${ }^{33}$ ) la acogen, aunque Figueiredo da una definición demasiado somera. En fin, el problema es éste: el cast. parva tiene en algunos sitios un sentido igual al del gall. y port. parga: parece que deben tener un origen común.

Conozco el apellido gallego Parga y también como nombre de lugar y de río. Un amigo mío, un poco farfullero, me asegura que existen también Parguiña y Parguiñas como apellidos. No será quizá confusión con Pardiña y Pardiñas ${ }^{34}$ ?

Aun dos preguntas: ¿Conoce V. el adj. lercioso empleado en el Este de Lugo? Se aplica allí al árbol ${ }^{(1)}$, etc. que está sobre un precipicio, por lo que da miedo subir a él. ¿Cómo se expresaría la misma idea en su región de V.?

29 Pregunta polos 24 fascículos do Diccionario gallego-castellano da Real Academia Galega (1913-1928), obra interrompida na voz cativo. Contén máis de 11.600 entradas.

30 É o Boletín de la Comisión Provincial de Monumentos Históricos y Artísticos de Orense (1898-1960).

31 O poema "Pan galego" publicouse en 1946 no no 1 da revista Gelmírez, segundo as informacións de Alonso Montero (2000: 88), quen tamén deu a coñecer o facsímil desta carta (2000: 194-195). Os versos son o xermolo doutra peza poética maior editada recentemente como Xeórxicas do pan (2013).

32 As voces meda e eirado aparecen nos versos 28 e 29 do poema.

33 Refírese ás obras de Antonio Moraes Silva, Diccionario da lingua portugueza (1789), e de Cândido de Figueiredo, Novo diccionário da língua Portuguesa (1899).

34 Estaba no certo o "amigo farfullero" que cita Dámaso. Na Cartografia dos apelidos de Galicia (http://ilg.usc. es/cag/), recóllense actualmente 34 ocorrencias do apelido Parguiña e 10 de Parguiñas. 
¿Cómo dicen ahí al 'separar el ganado menor de cada dueño cuando vuelven juntas de pastar las ovejas o cabras de todos los dueños del pueblo' las palabras que conozco son: xebrar (Oriente de Lugo) acibar (Oeste de Lugo y hacia Orense) chivar (Coruña); estremar (en algunos sitios de Pontevedra y en otros de Portugal), y dos o tres formas más, más raras. (¡Todo esto, vivísimo en Galicia, falta en los diccs.!) En cada sitio hay una interjección correspondiente para mandar al ganado que se separe (¡xebra!, ¡aciba!, etc.)

Dígame le ruego si para el destete de los terneros se usa en algún sitio el untar la ubre con sustancias amargas o de sabor repugnante.

¡Qué latazos le doy! Pero es V. uno de mis pocos recursos. Contésteme a esto (sobre todo a lo de la adjunta cuartilla, por lo que más quiera). Dígame en cada caso el lugar exacto donde se usa la palabra.

Un fuerte abrazo de

\section{Dámaso Alonso}

Quizá después de contestar pudiera V. enviar la adjunta hoja a algún amigo de región alejada para que contestara también. Yo se la envío a Alvaro Iglesia [sic] ${ }^{35}$, que me dará datos de Abadín, espero.

(1) También un sitio o paso muy malo, por donde es peligroso pasar [nota do propio Dámaso Alonso]

[En cuartilla á parte, mecanografada].

Ruego que al contestar me localice exactamente cada voz.

1) ¿Cómo se llaman los montones de mollos de centeno, trigo, etc. que se forman en el mismo campo donde se siega?

2) ¿Cómo se llaman los montones en que se depositan las mismas mieses en la eira antes de mallar?

3) ¿Cómo llaman a las mismas mieses cuando están ya extendidas sobre la era para mallar y durante la misma operación de mallar? Conozco el nombre eirada. ¿Hay algún otro?

4) En Castilla, después de la trilla se recoge el grano mezclado con la paja desmenuzada, antes de aventar, formando un montón. Ahí donde con el mallo no rompen, supongo, más que la parte de la espiga, supongo que la llevarán en seguida para formar palleiros. Pero ¿forman quizá montones con el grano aun sin cribar, es decir, mezclado con partículas de paja, etc.? En caso afirmativo, ¿cómo llaman a esos montones?

Le ruego tenga en cuenta todo esto, porque ocurre que en Castilla llaman parva al núm. 3, pero en Tierra de $\operatorname{Campos}^{36}$ al núm. 4, y en algún sitio de Galicia, según creo, al núm. 1 y también al dos. Carré da como equivalentes meda, parga y murgueiro, todos con el sentido del núm. 1 (y quizá del 2). Por su parte Valladares ${ }^{37}$ registra par$v a$, con sentidos iguales en Castilla (pero Carré la ha omitido) y como digo antes una aldeana de la prov. de Lugo me asegura que en su pueblo se dice parva con el sentido $\mathrm{n}^{\mathrm{o}} 1$ (= meda). En vocabs. dialects. port. se registra parga con el sentido de mi num. 4. (montón de paja y grano mezclados después de la trilla y antes de aventar).

Yo le rogaría que preguntara a aldeanos de sitios gallegos bien alejados entre si, y que conozcan bien estas labores. Creo recomendable hacer las preguntas como van

Cremos que alude ó profesor, poeta e tradutor Aquilino Iglesia Alvariño (1909-1961).

Tierra de Campos é unha comarca natural que se estende por Palencia, Valladolid, Zamora e León.

Refírese ó Diccionario gallego-castellano (1884) de Marcial Valladares. 
aquí, sin mencionar las voces parga y parva. Es posible que no las conozcan. De todos modos si esas voces no salen en la contestación, será bueno preguntar luego si las conocen. Fíjese bien si pronuncian parva o parga. También sería posible que usasen esas palabras no para centeno etc, sino para montones o ruedos extendidos en el suelo, de castañas o flor caída del árbol, o estiércol, o simplemente con el sentido de montón. Estas acepciones serían interesantes caso de existir. (No interesa en cambio parva "desayuno o trago de aguardiente por la mañana", que suele existir en toda la Península. 